\title{
PENGARUH PERAWATAN METODE KANGURU TERHADAP PENINGKATAN BERAT BADAN BBLR PADA RUANG PERINATOLOGI RSUD MUHAMMAD SANI KABUPATEN KARIMUN TAHUN 2019
}

\author{
Mira Agusthia ${ }^{1,}$ Rachmawaty M. Noer ${ }^{2}$, Intan Susilawati ${ }^{3}$ \\ STIKes Awal Bros Batam, RSUD Karimun
}

\begin{abstract}
ABSTRAK
Berat badan bayi merupakan salah satu hal pertama yang dinilai untuk mengambarkan derajat atau status kesehatan bayi baru lahir, oleh karena itu Bayi Berat Lahir Rendah (BBLR) dapat menjadi permasalahan. Menurut World Health Organization (WHO) diperkirakan sebanyak 20,6 juta bayi lahir setiap tahunnya adalah BBLR, dan hampir sepertiganya meninggal sebelum status kesehatannya stabil atau dalam 12 jam pertama kehidupan bayi. Untuk dapat mencapai kondisi kesehatan stabil dan berat badan normal, BBLR membutuhkan upaya pelestarian suhu tubuh, pemberian nutrisi dan pencegahan dari infeksi. Perawatan Metode Kanguru merupakan salah satu metode yang dapat memenuhi kebutuhan tersebut. Penelitian ini bertujuan untuk mengetahui pengaruh Perawatan Metode Kanguru terhadap peningkatan berat badan BBLR diruang Perinatologi RSUD Muhammad Sani. Desain penelitian yang digunakan Quasieksperimen pre test post test without control. Populasi dalam penelitian ini adalah semua bayi dengan berat badan lahir 1500 - 2500 gram. Sampel sebanyak 17 bayi dengan menggunakan teknik Total Sampling.. Data di kumpulkan dengan lembaran observasi, diolah dan dianalisa secara komputerisasi. Hasil analisa univariat diketahui rerata berat badan bayi sebelum dilakukan Perawatan Metode Kanguru (PMK) adalah 173,652 gram, dan sesudah dilakukan PMK interminten 2 jam perhari selama 7 hari, rerata berat badan meningkat menjadi 1861,76 gram. Terdapat perbedaan rerata berat badan sebelum dan sesudah sebesar 129,118 gram. Hasil uji paired t test adalah $\mathrm{p}=0,000>0,05$. Disimpulkan bahwa ada pengaruh PMK terhadap peningkatkan berat badan BBLR di Ruang Perinatologi RSUD Muhammad Sani Tahun 2019. Diharapkan Rumah Sakit menerapkan semua Komponen Perawatan Metode Kanguru dan mengevalusi atas implementasinya.
\end{abstract}

Kata Kunci : Perawatan metode kanguru, Berat badan, BBLR

\section{ABSTRACT}

Infant weight is one of the first things assessed to describe the degree or health status of a newborn, therefore Low Birth Weight Babies (LBW) can be a problem. According to the World Health Organization (WHO), it is estimated that 20.6 million babies are born each year are $\angle B W$, and nearly one third die before their health status is stable or within the first 12 hours of a baby's life. To be able to achieve stable health conditions and normal weight, LBW requires efforts to preserve body temperature, nutrition and prevention of infection. Kangaroo Mother Care $(K M C)$ is one method that can meet these needs. This study aimed to determine the effect of Kangaroo Mother Care on weight gain of $L B W$ in Perinatology. The research design used was 
Quasi-experimental pre-test post-test without control. The population in this study were all babies with birth weight 1500 - 2500 grams. There were 17 infants using the Total Sampling technique. Data were collected using observation sheets, then processed and analyzed computerized. The univariate analysis showed that the average baby's weight before the Kangaroo Mother Care was 173,652 grams, and after KMC average baby's body weight increased to 1861.76 grams. There are differences in the average weight of babies before and after 129,118 grams. Paired t test results are $p=0,000>0.05$. It was concluded that there was an influence of KMC on increasing LBW weight. It is expected that the Hospital will implement all Components of the Kangaroo Mother Care and evaluate its implementation.

Keywords: Kangaroo Mother Care, Weight, LBW

\section{PENDAHULUAN}

BBLR (Bayi Berat Lahir Rendah) diartikan sebagai bayi yang lahir dengan berat badan kurang dari 2.500 gram. BBLR menjadi prediktor tertinggi angka kematian bayi terutama pada bulan pertama kehidupan. Berdasarkan studi epidemiologi, BBLR mempunyai resiko kematian 35 kali lebih besar dibandingkan dengan bayi yang lahir dengan berat badan normal bulan. Berdasarkan hasil utama riset kesehatan dasar Kementerian Kesehatan Republik Indonesia ( 2018 ) bahwa grafik proporsi berat badan lahir tahun 2007-2018 mengalami peningkatan dari angka 5,4\% menjadi $6,2 \%$ kejadian, yang dihitung berdasarkan $56,6 \%$ bayi yang memiliki catatan lahir. Proporsi berat badan lahir $<2500$ gram (BBLR) pada anak umur 0-59 bulan terendah adalah provinsi Jambi dengan $2.6 \%$ dan yang tertinggi adalah di provinsi Sulawesi utara dengan angka 8,9\%, angka ini lebih tinggi dari target Rencana Pembangunan Jangka Menengah Daerah Tahun 2019 yakni 8\%. Sedangkan provinsi Kepulauan Riau berada pada peringkat keenam angka BBLR tertinggi di Indonesia.

Pada wilayah Kabupaten Karimun dilaporkan bahwa Penyebab kematian bayi tertinggi tahun 2017 dan 2018 adalah BBLR, dimana kematian itu terjadi pada kurang dari hari ketujuh setelah kelahiran bayi. Status kesehatan BBLR dipengaruhi oleh ketidakmemampuan bayi dalam proses adaptasi dari kehidupan di dalam uterus ke lingkungan ekstrauterin. Kegagalan adaptasi merupakan konsekuensi dari anatomi dan fisiologi sistem tubuh yang belum matang. Masalah yang sering ditemukan adalah ketidakstabilan suhu tubuh, masalah pernafasan, masalah pencernaan dan immunitas. Oleh karena itu BBLR perlu penatalaksanaan khusus agar tidak terjadi gangguan tumbuh kembang bahkan kematian. Semakin kecil berat badan bayi dan semakin prematur bayi, maka semakin kompleks perawatan yang diperlukan.

Pemberian nutrisi secara dini dianjurkan untuk mencegah terjadinya hipoglikemia, hiperbilirubinia dan membantu pertumbuhan hingga mencapai berat badan normal. ASI merupakan pilihan nutrisi pertama bagi BBLR sebagaimana bayi baru lahir secara umumnya. ASI dapat diberikan melalui sonde bagi BBLR yang reflek hisap dan menelannya masih lemah. BBLR secara relatif memerlukan lebih banyak kalori dibandingkan dengan bayi dengan berat lahir normal, karena diperlukan bayi untuk bertumbuh, berkembang dan meningkatkan ketahanan tubuh bayi terhadap infeksi. Kalori yang lebih banyak juga dibutuhkan bayi dalam mempertahankan suhu tubuhnya meskipun BBLR harus dibantu dengan menyediakan 
lingkungan yang dapat melestarikan suhu tubuh normalnya.

Upaya Pelestarian suhu tubuh BBLR dapat dilakukan dengan cara penggunaan alat radiant warmer, penggunaan inkubator, topi penutup kepala, plastic warb dan perawatan metode kanguru. Penggunaan radiant warmer dan plastic warb efektif untuk perawatan bayi prematur segera setelah lahir, sedangkan pengelolaan panas untuk perawatan rutin disarankan penggunaan inkubator atau perawatan metode kanguru.

Survey pendahuluan yang dilakukan di ruangan perinatologi RSUD Muhammad Sani ditemui empat orang BBLR, satu diantaranya sudah boleh pulang karena grafik kenaikan berat badan cenderung meningkat dan keluarga mengatakan akan bergantian melakukan PMK dirumah. Dua diantaranya yang masih dirawat, mengalamai kenaikan berat badan setelah diberikan PMK. Salah satu ibu bayi mengatakan bahwa pada awal melakukan PMK dia merasa takut dan tidak percaya bahwa metode sederhana ini akan membatu menaikan berat badan bayi lebih cepat, namun setelah PMK dilakukan selama 3 hari dan petugas mengatakan berat badan bayinya mengalami kenaikan, ibu menjadi yakin dan bersemangat untuk melakukan PMK. Ibu lainya mengatakan hal yang sama namun karena kondisinya, bayi harus tetap berada di rumah sakit sedangkan ibu sudah diperbolehkan pulang ke rumah. Ibu mengunjungi bayi setiap hari untuk melakukan PMK dan memberi ASI. Berbeda halnya dengan bayi ketiga yang belum menunjukan kenaikan berat badan walaupun sudah dirawat selama 5 hari dalam inkubator dan dilakukan PMK interminten. Petugas perinatologi mengatakan bahwa sejak PMK diterapkan banyak dijumpai ibu yang belum yakin dengan manfaat PMK walaupun petugas sudah melakukan edukasi. Keyakinan ibu dapat timbul setelah melakukan komunikasi dengan ibu yang sudah membuktikan bahwa PMK dapat meningkatkan berat badan bayinya. Menurut Kepala Ruangan Perinatologi PMK dapat membantu meningkatkan berat badan bayi, meskipun pemantauan yang ketat untuk pemenuhan nutrisi bayi, namun belum pernah dilakukan penelitian untuk menilai pengaruh PMK tersebut terhadap peningkatan berat badan bayi.

Berdasarkan latar belakang sebagaimana telah diuraikan diatas maka peneliti tertarik untuk melakukan penelitian tentang Pengaruh Perawatan Metode Kanguru (PMK) terhadap berat badan bayi baru lahir rendah di Ruang Perinatologi RSUD Muhammad Sani Kabupaten Karimun tahun 2019.

\section{METODE PENELITIAN}

Desain penelitian yang digunakan adalah desain quasi eksperimen pre and post test without control, yaitu penelitian yang menguji coba suatu intervensi/perlakukan pada satu kelompok tanpa adanya kelompok pembanding dan tidak dilakukan secara random. Pengaruh perlakuan dinilai dengan cara membandingkan nilai post test dengan pre test.

Sampel penelitian adalah sekelompok individu yang merupakan bagian dari populasi terjangkau dimana peneliti langsung mengumpulkan data atau melakukan pengamatan/pengukuran pada unit ini. Pada penelitian ini sampel adalah total sampling, dengan kriteria yang digunakan adalah sebagai berikut:

a. Kriteria inklusi : Neonatus dengan berat badan < 2.500 gram, Orang tua bayi bersedia menjadi responden

b. Kriteria eksklusi : Bayi yang sedang dalam perawatan khusus, Bayi dengan berat badan $<1.500$ gram, Ibu dengan penyakit menular. 
Alat pengumpul data yang digunakan dalam peneltian ini adalah Standar Operasional Prosedur (SOP) rumah sakit sebagai panduan pelaksanaan, timbangan bayi untuk mengukur berat badan BBLR dan lembar observasi untuk mencatat hasil penelitian. Data pre test didapat dengan menimbang berat badan bayi sebelum pelaksanaan perawatan metode kanguru, intervensi PMK interminten diberikan kepada bayi 2 jam perhari selama 7 hari, dan data post test didapat setelah BBLR ditimbang pada hari ke 8. Penimbangan post test dilakukan oleh petugas perinatologi sebagai asisten peneliti dalam penelitian ini.
Data yang sudah terkumpul dianalisa dengan menggunakan uji statistik paired t test.

\section{HASIL DAN PEMBAHASAN}

\section{Analisis Univariat}

Berdasarkan Tabel 1 diketahui bahwa frekuensi tertinggi ibu yang memiliki BBLR merupakan kelompok umur 20- 35 tahun sebesar 82,35\%. Mayoritas ibu berpendidikan SLTP, sebagain besar ibu tidak bekerja dan Paritas Multipara (G2-G4) sebesar 70,59\%.

Tabel 1

Karakteristik Ibu dengan BBLR

berdasarkan Umur, Pendidikan, Paritas dan Pekerjaan

\begin{tabular}{llcc}
\hline No. & \multicolumn{1}{c}{ Variabel } & f & $\%$ \\
\hline 1. & Umur Ibu & & \\
\hline & $>20$ tahun & 1 orang & 5,88 \\
& $20-35$ tahun & 14 orang & 82,35 \\
& $<35$ tahun & 2 orang & 11,76 \\
\hline 2. & Pendidikan Ibu & & \\
\hline & SD & orang & 11,76 \\
& SLTP & 8 orang & 47,06 \\
& SLTA & 7 orang & 41,18 \\
\hline 3. & Kehamilan & 3 orang & 17,65 \\
\hline & Primipara & 12 orang & 70,59 \\
& Multipara & 2 orang & 11,76 \\
\hline & Grande Multipara & & \\
\hline 4. & Pekerjaan Ibu & 9 orang & 47,94 \\
\hline & Tidak Bekerja Bekerja & 8 orang & \\
\hline
\end{tabular}


Ibu bayi dengan BBLR pada peneltian ini merupakan kelompok usia reproduksi sehat yaitu 20 sampai dengan 35 tahun. Ibu pada usia ini memiliki organ reproduksi yang telah mampu untuk memproses kehamilan dan persalinan secara baik dan belum mengalami penurunan fungsi organ reproduksi yang dapat menjadi salah penyebab BBLR. Penelitian yang dilakukan oleh Susilowati (2016) tentang faktor resiko yang berhubungan dengan kejadian berat badan lahir rendah pada noenatus yang dirawat di RSUP Prof. Dr. R. Kandau juga menemukan karakterikstik umur ibu yang sama dengan hasil penelitian ini yaitu kelompok usia ibu yang paling banyak melahirkan neonatus dengan BBLR adalah kelompok usia 20-35 tahun dengan jumlah 37 kasus atau sebesar $60 \%$ dari total jumah responden. Hal yang sama juga dapat dilihat dari hasil penelitian Putri (2017) bahwa 82,29\% dari responden yang melahirkan BBLR merupakan kelompok umur 20-35 tahun.

Menurut Mahayana (2016) Saat ini tidak adanya etilogi pasti antara penyebab PJT dan prematuritas, sehingga banyak faktor resiko yang dikemukakan dengan berbagai macam patogenesis yang berkeitan dengan kejadian BBLR. Faktor resiko yang mempengaruhi kedua kejadian tersebut sulit dipisahkan secara tegas dalam kontribusinya sebagai penyebab BBLR. Peneltian yang dilakukan di brazil oleh Sclowitz et al, memberikan hasil bahwa presentase BBLR yang cukup besar $(67,6 \%)$ pada ibu yang mengalami anemia dan janin yang berjenis kelamin laki-laki. Namun terdapat faktor resiko lain yang tidak lebih dari 50\% seperti : usia ibu yang kurang dari 20 tahun dan lebih dari 35 tahun sebesar 13,5\%, paritas grandemultipara sebesar $22,3 \%$, riwayat abortus $22,7 \%$, pendidikan rendah $23,4 \%$ dan status sosiso ekomoni rendah sebesar $15,4 \%$.

Menurut analisa Peneliti bahwa usia ibu bukanlah penyebab utama kejadian BBLR pada penelitian ini. Karena selain umur masih banyak faktor resiko yang tidak peneliti ambil datanya. Seperti riwayat kesehatan ibu, sosioekonomi, dan faktor kebiasaan ibu. Namun ada sebesar $17 \%$ dari responden penelitian ini yang merupakan ibu dengan kategori reproduksi yang beresiko ( $<20$ tahun dan $>35$ tahun). Meningkatnya usia ibu akan menyebabkan terjadinya perubahan - perubahan pada pembuluh darah dan juga ikut menurunnya fungsi hormon yang mengatur siklus reproduksi (endometrium). Semakin bertambahnya usia seorang wanita, maka hormon pengatur siklus reproduksi juga semakin menurun. Apabila kadar esterogen rendah dan perkembangan endometrium tidak sempurna, maka aliran darah ke uterus juga akan ikut menurun sehingga dapat mempengaruhi penyaluran nutrisi dari ibu ke janin, yang memicu terjadinya BBLR.

Berdasarkan tabel 2 dapat dilihat bahwa sebelum pelaksanan PMK dimulai sebagain besar bayi berumur 1-3 hari. $58,82 \%$ bayi dilahirkan prematur dan bayi jenis kelamin laki laki lebih banyak dari pada perempuan. 
Tabel 2

Karakteristik BBLR Menurut

Umur Bayi, Umur Kehamilan dan Jenis Kelamin

\begin{tabular}{llcc}
\hline No. & \multicolumn{1}{c}{ Variabel } & f & $\%$ \\
\hline 1. & Umur Bayi & & \\
\hline & 1 - 3 hari & 10 orang & 58,82 \\
& $4-6$ hari & 5 orang & 29,41 \\
& $7-10$ hari & 2 orang & 11,76 \\
\hline 2. & Umur Kehamilan & & \\
\hline & Prematur & 10 orang & 58,82 \\
& Dismatur & 7 orang & 41,18 \\
\hline 3. & Jenis Kelamin & & \\
\hline & Laki - laki & 9 orang & 52,94 \\
& Perempuan & 8 orang & 47,06 \\
\hline
\end{tabular}

Tabel 3

Perbedaan Rerata Berat Badan Bayi Baru Lahir Sebelum dan Sesudah Pelaksanaan Perawatan Metode Kanguru

\begin{tabular}{|c|c|c|c|c|c|}
\hline Variabel & $\mathrm{N}$ & Mean & Mean Diffrent & Standar Deviasi & $P$ value \\
\hline $\begin{array}{l}\text { Berat Badan } \\
\text { Sebelum }\end{array}$ & \multirow{2}{*}{17} & 1732,65 & \multirow{2}{*}{129,118} & 194,126 & \multirow{2}{*}{0,000} \\
\hline $\begin{array}{l}\text { Berat Badan } \\
\text { Sebelum }\end{array}$ & & 1861,76 & & 164,68 & \\
\hline
\end{tabular}

Berdasarkan tabel 3 diketahui bahwa rata-rata berat badan bayi sebelum sebelum pelaksanaan perawatan metode kanguru adalah 1732,65 gram. Sedangkan rata-rata berat badan bayi sesudah perawatan metode kanguru adalah 1861,76 gram. Terlihat perbedaan rata-rata (mean different) berat badan sebelum dan sesudah pelaksanaan perawatan metode kanguru adalah 129,118 gram. Nilai $p=0,000(p<0,05)$, disimpulkan bahwa ada perbedaan rata-rata berat badan bayi baru lahir rendah sebelum dan setelah pelaksanaan Perawatan Metode Kanguru (PMK) di Ruang Perinatologi
RSUD Muhammad Sani Kabupaten Karimun tahun 2019.

\section{Rerata berat badan BBLR sebelum Perawatan Metide Kanguru}

Hasil Penelitian ini sejalan dengan penelitian Silvia (2015) tentang Pengaruh Perawatan Metode Kanguru Terhadap Perubahan Berat Badan Bayi Lahir Rendah, di Ruang Perinatology RSUD Dr.Achmad Mochtar Bukittinggi yang rata-rata berat badan bayi sebelum perawatan metode kanguru adalah 1.738,60 gram. Penelitian 
yang dilakukan oleh Sari (2015) di Rumah Sakit Umum Haji Medan yang berjudul efektifitas perawatan metode kanguru dengan support binder (kain panjang batik/jarik) dalam peningkatan berat badan bayi lahir rendah didapat rata-rata berat badan bayi pre test yang lebih tinggi yaitu 2.026 gram.

Perawatan Metode Kanguru (PMK) merupakan perawatan suportif pengganti inkubator yang dilakukan dengan meletakan bayi diantara kedua payudara ibu sehingga sehingga terjadi kontak langsung kulit ibu dan kulit bayi. PMK memiliki keuntungankeuntungan apabila dibandingkan dengan inkubar yaitu dapat meningkatkan hubungan emosional ibu dan anak, menstabilkan suhu tubuh, denyut nadi, jantung dan pernafasan bayi, mengurangi stress pada ibu dan bayi, mengurangi lama menangis pada bayi, memperbaiki hubungan emosi antara ibu dan bayi serta meningkatkan pertumbuhan berat badan karena pemakaian kalori atau energi berkurang. Proses peningkatan berat badan sangat di dukung oleh terpenuhinya kebutuhan nutrisi bayi. PMK membuat bayi menyusu ke ibu lebih lama dan sering sehingga bayi menjadi tenang dan mendapat suplay ASI yang mencukupi. Energi yang diperoleh tubuh hanya difokuskan untuk pertumbuhan. Bayi yang diberikan PMK mempunyai suhu yang relatif normal, denyut jantung dan pernafasan teratur, tidur lebih lama dan sedikit menangis. PMK pada BBLR akan menyebabkan peningkatan kadar glukosa yang menyebabkan metabolisme sel menjadi baik sehingga pertumbuhan berat badan akan lebih baik juga.

\section{Rerata berat badan BBLR sesudah Perawatan Metide Kanguru}

Hasil penelitian ini didukung oleh Astuti (2015) yang menelti tentang Pengaruh Penerapan Perawatan Metode
Kanguru Terhadap Peningkatan Berat Badan Bayi Lahir Rendah, di RS PKU Muihamadiyah Gombong yaitu dari 18 orang bayi yang diberikan PMK selama 7 (tujuh) hari terjadi peningkatan berat badan sebesar 1.257,50 gram. Hal yang sama ditunjukan oleh Mardiani (2017) di Ruang Perinatologi RSUD DR. Rasyidin Padang, yaitu terdapat kenaikan rerata berat badan bayi setelah PMK selama 10 hari menjadi 2.270 gram dari yang sebelum dilakukan PMK yaitu 1.871,33 gram. Penelitian yang dilakukan oleh Huniyah (2018) juga menunjukan hasil yang sejalan dengan penelitian ini, terjadi peningkatan berat badan seluruh responden yang diberikan PMK selama 30 hari yang berkisar antara 50-350 gram pada BBLR di Ruang Hasyim Asy'ari RSI Sakinah Mojokerto pada Bulan Juli 2017.

Penelitian yang dilakukan oleh Armi (2015) tentang pengaruh PMK terhadap perubahan berat badan BBLR pada ruang perina A dan NICU Rumah Sakit Umum Kabupaten Tangerang, didapat hasil yang tidak sejalan dengan penelitian ini, yaitu berat badan setelah dilakukan PMK menjadi 1.496 dari yang sebelumnya adalah 1.641 gram. Sedangkan pada BBLR yang hanya di berikan PMK tanpa terapi murotal selama 3 hari oleh Putriana di RSU H. Abdul Moeloek Provinsi Lampung tidak mengalami kenaikan berat badan.

Pada penelitian ini hampir semua bayi mengalami kenaikan berat badan setelah dilakukan PMK, hanya 3 orang bayi saja dari 17 orang responden yang tidak mencukupi target kenaian berat badan (40 Gram). Peningkatan berat badan berbeda antara satu bayi dengan bayi lainnya. Perbedaan peningkatan berat badan tersebut dapat dipengaruhi oleh umur bayi pada waktu di berikan PMK kurang dari 10 hari sedangkan menurut Mutmainah (2015) secara normal bayi yang lahir cukup bulan maupun bayi berat lahir rendah (BBLR) 
akan mengalami kehilangan berat badan sekitar $5-10 \%$ pada 7 hari pertama kehidupanya, dan berat badan lahir akan kembali di hari 7-10. Menurut Peneliti hari ke 10 adalah waktu yang tepat memulai PMK apabila ingin mengukur pengaruhnya terhadap peningkatan berat badan bayi.

\section{Analisa Pengaruh Perawatan Metode Kanguru terhadap Berat Badan BBLR}

Hasil peneltian ini sejalan dengan peneltian yang dilakukan oleh Huniyah (2018) menunjukan hasil seluruh responden mengalami peningkatan berat badan yang berkisar antara 50-350 gram setelah dilakukan PMK di Ruang Hasyim Asy'ari RSI Sakinah Mojokerto pada Bulan Juli 2017. Hasil uji paired t test diperoleh nilai $p=0,000$ dengan kesimpulan terdapat pengaruh yang signifikan PMK terhadap peningkatan berat badan BBLR. Hasil berbeda di kemukakan oleh Anggraini (2015) yang meneliti tentang efektifitas PMK terhadap peningkatan berat badan BBLR di Rumah Sakit Muhammadiyah Palembang yang diberikan selama 10 hari, berdasarkan uji statistik di dapat nilai $\mathrm{p}=$ 0,272 yang berarti tidak terdapat pengaruh PMK terhadap peningkatan berat badan BBLR.

Berdasarkan analisa peneliti adanya pengaruh pelaksanaan metode kanguru terhadap berat badan bayi karena selama pelaksanaan metode kanguru tersebut terjadi kontak erat dan interaksi ibu dan bayi yang membuat bayi merasa nyaman dan aman, serta meningkatkan perkembangan psikomotor bayi sebagai reaksi rangsangan sensoris dari ibu ke bayi. Dengan melakukan PMK, proses menyusui lebih berhasil, karena proses menyusui menjadi lebih lama. Setelah bayi menunjukkan tanda kesiapan untuk menyusu, dengan menggerakkan lidah dan mulut, dan keinginan untuk menghisap, bayi dapat secara langsung menghisap puting susu ibu dan memperoleh ASI yang dibutuhkannya. Semakin bayi sering menyusu maka produksi ASI akan meningkat dan dapat mencukupi kebutuhan nutrisi bayi. Dengan demikian, melalui PMK tersebut maka kebutuhan nutrisi bayi yang sesuai dan adekuat akan menjamin tumbuh kembang optimal. Pendapat ini didukung oleh study yang dilakukan oleh Syaiful (2018) yang mengatakan PMK mempunyai pengaruh yang signifikan dalam meningkatkan keberhasilan pemberian ASI pada BBLR.

Disamping itu, bayi dengan perawatan metode kanguru mempunyai suhu tubuh relatif normal, denyut jantung dan pernafasan teratur, sehingga dapat menyebabkan peningkatan kadar glukosa lebih tinggi pada bayi. Peningkatan kadar glukosa akan menyebabkan sel melakukan metabolisme dengan baik sehingga proses pertumbuhan sel menjadi lebih baik. Kenaikan berat badan bayi juga terjadi karena bayi dalam keadaan rileks dengan posisi kanguru, terjadinya ikatan emosional antara ibu dan bayi menyebabkan kegelisahan dan stres bayi berkurang, sehingga bayi lebih banyak istirahat/tidur, sehingga menunjang pertumbuhan dan perkembangan bayi. Hal ini berdasarkan pengamatan peneliti setiap bayi yang diberikan PMK akan langsung tertidur dengan nyaman dalam dekapan ibu.

\section{SIMPULAN}

Berdasarkan hasil penelitian dan pembahasan yang telah diuraikan diatas maka diperoleh kesimpulan bahwa ada pengaruh pelaksanaan perawatan metode kanguru terhadap peningkatan berat badan BBLR di ruang perinatologi RSUD Muhammad Sani Kabupaten Karimun Tahun 2019.

Saran bagi peneliti selanjutnya Agar hasil peningkatan berat badan lebih akurat disarankan untuk melakukan intervensi 
PMK pada bayi berumur diatas 10 hari pada saat penurunan berat badan bayi secara fisiologis sudah tidak terjadi lagi. Bagi fasilitas kesehatan agar dapat menerapkan seluruh komponen kanguru dan melakukan evaluasi atas implementasinya.

\section{UCAPAN TERIMA KASIH}

Terima kasih kepada Direktur RSUD Muhammad Sani yang telah memberikan izin untuk menjadikan RSUD Muhamamad Sani sebagai lahan penelitian. Selanjutnya kepada seluruh petugas perinatologi yang telah membantu kelancaran penelitian ini. Ucapan terima kasih juga peneliti sampaikan kepada STIKes Awal Bros batam yang telah membantu dalam publikasi hasil peneltian.

\section{DAFTAR PUSTAKA}

Anisa, Oktiawati, and Julianti. 2017. Teori Dan Aplikasi Perawatan Bayi Prematur. Cetakan Pe. ed. Ismail Taufik. Jakarta: CV. Trans Info Media.

Angraini, "Efektifitas Metode Kanguru Terahadap Peningkatan Berat Badan Pada Bayi dengan Berat Lahir Rendah di Rumah Sakit Muhammdiyah Palembang 2105" Cendika Medika Volume 2 No 2, september 2017 ISSN: 2503-1392.

Atika, Manggiasih, and Jaya 2016. Asuhan Kebidanan Pada Neonatus, Bayi, Balita Dan Anak Pra Sekolah. Cetakan Pe. ed.

Erni, Hernawati, and Kamila, 2017. Buku Ajar Bidan Kegawatdaruratan Maternal Dan Neonatal. Cetakan Pe. ed. Wahyudi Ahmad. Jakarta Timur: CV Trans Info Media.
Hastuti, Purwandani, Riza, Yuli "Pendidikan Kesehatan Meningkatkan Praktek Perawatan Metode Kanguru (PMK) Pada Ibu Nifas Dengan Bayi Berat Lahir Rendah" Jurnal Riset Kesehatan volume 7, Nomor 1, 2018 32-36

Kemenetrian Kesehatan, Badan Penelitian dan Pengembangan. 2018. "Hasil Utama Riset Kesehatan Dasar." Kementrian Kesehatan Republik Indonesia: 1-100.

Kesehatan Masyarakat, Jurnal et al. 2018. "Kangaroo Mother Care Pada Bayi Berat Lahir Rendah : Sistematik Review Kangaroo Mother Care In Low Baby Weight: A Systematic Review." Artikel XI 8(1): 83-96. http://jurnal.unismuhpalu.ac.id/index.p hp/PJKM.

Kusuma Kelana Dharma. 2017. Metodologi Penelitian Keperawatan, Panduan Melaksanakan Dan Menerapkan Hasil Penelitian. Revisi Tah. Jakarta Timur: Trans Info Media, Jakarta.

Madjid, AD, Alasiry, and Febriani. 2015. "Manual Keterampilan Klinik Teknik Perawatan Metode Kanguru." CSL Siklus Hidup Fakultas Kedokteran Universitas Hasanuddin, Makasar.

Mahayana, Chundrayetti, Yulistini. 2015. "Artikel Penelitian Faktor Risiko Yang Berpengaruh Terhadap Kejadian Berat Lahir Rendah." http:jurnal.fk.unand.ac.id

Wibowo, Pratitis, Luthfia, Wahyuni, Tarmali Auly "Faktor Ibu Terhadap kejadian Bayi Berat Lahir Rendah". Higeia Journal Of Publik Health Research And Delelopment HIGEA 3 (1) 2019. 
Putriana Yeyen, Aliyanto "Efektifitas Perawatan Metode Kanguru (PMK) dan Terapi Murottal terhadap Peningkatan Berat Badan dan Suhu Tubuh Pada Bayi BBLR". jurnal Kesehatan volume 9, Nomor 1, april 2018 ISSN 2086 (Prnt), ISSN 25485695 (Online)

Kurnia, Muharry 2018. "Hubungan Karakteristik Ibu Dengan Kejadian BBLR Di wilayah Kabupaten Kuningan" jurnal Kesehatan Bakti Husada Vol. 09 No. 02 Desember 2018

Sari Indah Dewi, Listriarini Dwi Utary 2018. "Efektifitas Perawatan Metode Kanguru Dengan Support Binder (kain panjang Batik/jarik) Dalam Peningkatan Berat Badan Bayi Lahir Rendah Di RSU Haji Medan"' jurnal Kesehatan global, Medan Vol.1, januari 2018: 15-20

Sembiring, Julliana $\mathrm{Br}$, Debby Pratiwi, Aprilia Sarumaha. 2017. Hubungan Usia, Paritas dan Usia Kehamilan Dengan Bayi Berat Lahir Rendah di RSU Mitra Medika Medan.Jurmal Bidan Komunitas Vol. II No. 1 Hal. 38-46, e-ISSN 2614-7874.

Silvia, Putri, Yelmi, Elharisda. 2015. "Pengaruh Perawatan Metode Kanguru Terhadap Perubahan Berat Badan Bayi Lahir Rendah. Jurnal Ipteks Terapan V9,il (11-19) ISSN : 1979-9292 E-issn : 1460-5611

Susilowati Enny, Wilar Rocky, Salendu Praevilia. " Faktor Resiko yang Berhubungan Dengan Kejadian berat Badan Lahir Rendah pada Neonatus Yang Dirawat di RSUP Prof. Dr. R. D. kandau Periode Januari 2016 - Juli 2016. Jurnal e-Clinic (eCI), Volume 4, Nomor 2, Juli - Desember 2016.
Solfiana Juni, Hakim Mohammad, Mufdillah. "Pengaruh Keikutsertaan Suami Dalam Kangaroo Mother Care Terhadap Perubahan Berat Badan Pada Bayi Berat Lahir Rendah." The 7Thn University Research Colloqium 2018 STIKES PKU Muhammadiyah Surakarta

Solehati, Tetti, CE Kosasih, and Rais. 2018. "Kangaroo Morher Care Pada Bayi Berat Lahir Rendah Sistematik Review." Jurnal Kesehatan Masyarakat Volume 8, Nomor 1, juni 2018. ISSN 2089-0346 (Print)

Taufik Yuanita, Lilis Fatmawati, Mukhlisotin " Perawatan Metode Kanguru Meningkatkan Keberhasilan Pemberian ASI Pada BBLR" Journal Of Ners Community Volume 09, Nomor 01, Juni 2018 hal. 34-42

Udayana, Universitas. 2016. "Praktek Klinik Perawatan Metode Kanguru 1 Universitas Udayana." (September): 1-29.

Unhas, Fakultas Kedokteran, Fakultas Kedokteran, and Universitas Hasanuddin. 2016. "Manual Keterampilan Klinik Metode Kanguru" Makasar.

Vidia, Manggiasih Atika, and Jaya Pongki. 2016. Buku Ajar Asuhan Kebidanan Pada Neonatus, Bayi, Balita Dan Anak Pra Sekolah. Cetakan Pe. ed. Ismail Taufik. Jakarta Timur: CV Trans Info Media. 